\title{
Psychosocial workload of Swedish ambulance and emergency room personnel with high prevalence of dying, death and grieving relatives. A descriptive and comparison study
}

\author{
Ulf Erland Johansson ${ }^{1}$, Åsa Katarina Johansson ${ }^{2}$, Agneta Grimby² \\ ${ }^{1}$ Department of Medicine, Sahlgrenska Academy, Göteborg University, Sweden \\ ${ }^{2}$ Department of Geriatrics, Sahlgrenska University Hospital, Bruna stråket 11 B, 41345 Göteborg, Sweden
}

Email address:

agneta.grimby@telia.com (A. Grimby)

To cite this article:

Ulf Erland Johansson, Åsa Katarina Johansson, Agneta Grimby. Psychosocial Workload of Swedish Ambulance and Emergency Room Personnel with High Prevalence of Dying, Death and Grieving Relatives. A Descriptive and Comparison Study. American Journal of Nursing Science. Vol. 3, No. 5, 2014, pp. 56-65. doi: 10.11648/j.ajns.20140305.11

\begin{abstract}
Frequent caretaking of severely ill, dying, and dead people as well as bereaved close relatives could involve too much stress for emergency personnel to be satisfied with the job situation. Screening for critical aspects for work satisfaction and endurance at ambulance and emergency rooms would provide useful information to the workers themselves, their management, and for pre-hospital acute routines/programs. Two hundred and forty 40 -item job-related, postal enquieries on demographical, as psychological, social, economical, and existential work aspects were sent to 26 clinical directors to be assessed by personnel at the ambulance and emergency rooms in Sweden. The response rate was $64 \%$, the majority being nurses and nurse assistants, experiencing a very high, high, or rather high prevalence of severely ill or dead patients at their work place. The hospitals' frequency of severely ill or dead patients predicted a higher mental workload experience in both ambulance and emergency room personnel. More personnel at the emergency rooms compared with ambulance workers expressed time pressure and were less satisfied with their caretaking, two of three reporting their job to be mentally straining as compared with one of three among the ambulance personnel. Change of work due to heavy workload was reported by one in three. The majority thought they could get used to a job with death and grieving, wellbeing however negatively affected. Still, the majority reported good health and little sick leave due to excessive workload. Several critical factors seemed important for job satisfaction among Swedish ambulance workers and personnel at the emergency rooms. Complaints about psychological stress, physically high workload, physical damage, many working hours, low salary, much shift- and night work, better vacation leave, more resources, too little time for recovery, crisis support and guidance, better routines, more explicit care programs including improved bereavement support for relatives, better possibilities for job control, self-efficacy, unit efficiency, and clearer work duties, and a family-non-conflicting job situation could favour work performance in both groups.
\end{abstract}

Keywords: Ambulance Personnel, Emergency Room Personnel, Trauma, Bereaved Relatives, Psychosocial Workload, Dying, Death

\section{Introduction}

Loss by death is said to be the most stressful event in a person's life (1). The nearness of death often has detrimental effect on quality of life of all the involved people in the dying process: for the patient, the close relatives, and sometimes also the caring personnel. Preparatory grief is a common experience among families of terminally ill patients and is said to have many characteristics similar to grief reactions appearing after the loss (2).

Death may, however, sometimes occur unexpectedly and rapidly without any period of preparation. Sudden death may lead to complicated grief for those left behind, and cause stress for the professionals handling the acute situation $(3,4)$.

Since most health care professionals may be trained in emergency medicine where all efforts are employed to 
prolong life, they may not be comfortable caring for dying patients (5). Ambulance service workers and personnel at emergency rooms are frequently exposed to highly stressful situations during their everyday work activity. Exposure to critical incidents and traumas may in some emergency service personnel cause severe anxiety, PTSD symptoms, and a phenomenon designated "peritraumatic dissociation" (6). Maladaptive responses at critical incidents involving e.g. multiple casualties at disasters, children's' trauma, and prolonged extrication of trapped victim with life-threatening injuries, should be met with therapeutical treatment and longtime follow up to prevent burnout among the rescue personnel (7). A substantial number of ambulance service workers may need support in processing distressing incidents at work and may benefit from information that normalizes post-traumatic symptoms such as intrusive memories (8).

Professionals who work in situations that expose them to death have been of interest to traumatic stress research for many years. Various personal characteristics of stress preventive nature, as well as beneficial coping strategies in emergency service personnel have been shown to be crucial in research among emergency health care teams (9-11). However, the nature of these characteristics may vary and may also be difficult to separate. Farias and coworkers (12) reported that the emergency health care team workers' pain always resulted from emotional stress or appeared after providing emergency care, which suggests that the workers find it very difficult to differentiate physical from mental stress.

The factor of years at work tends to be of importance. Personnel with more work experience seem to have more positive attitudes toward death and caring for dying patients (13). Positive attitudes were significantly predicted by an approach acceptance death attitude and social support; negative ones were predicted by e.g. fear of death, intrusions and avoidance (14).

Studies on grief among professional carers reveal, among other things, loss of energy and well-being, particularly shown at inadequate preparation, problems with peers and supervisors, heavy workload, conflicts with physicians, uncertainty concerning treatment, patients and their families (15-17).

The most developed support systems seem to exist among palliative health care professionals $(18,19)$. However, a substantial subgroup of emergency service personnel may need support in processing distressing incidents at work and may benefit from information that normalizes post-traumatic symptoms such as intrusions (9). The best predictors of high stress scores among community working nurses were having an unsupportive line manager, working with a specific client group and, finally, not having job security (20). These findings indicate that there is a need to create more supportive environments both in terms of job security and management (21). Team reflective practices were also important in the support of their professional development (10). The contribution of the organizations in coping to lower stress, education and training may help the professionals deal with reactions of anxiety and improve their mental health in the most disturbing situations.

Lack of communication and coordination may threaten patient safety, and is often a disturbing factor to various caregivers (22). Prehospital triage to improve patient safety by shortened lead times associated with the handover of patient care between ambulance and emergency department. To be able to provide satisfactory care of dying people requires focus on several critical moments for personnel in emergency care. The resources of staff and economy seemed to be a constant challenge.

Comparisons of work burden, stress factors, and job exhaustion could be less meaningful without separating areas of care situations. In this study we focused on the caretaking by the Swedish ambulance personnel and the medical professionals at the emergency ward, each sector providing immediate help according to the personnel and instrumental equipment. The job often involves cases of life-threatening illnesses as well as accidents with high risk for the injured person's life, demanding fast and drastic action, short time span, as well as lack or uncertainty of resources available. The care in their respective areas also involves supportive actions for the close relatives of the person being wounded, severely ill or dead.

\section{Aim and Method}

\subsection{Aim}

The aim of the study is to record the occurrence of critical psychological, physical, social issues as well as other aspects (e.g. financial, personnel, and educational resources) by the two types of rescue personnel, the ambulance workers and the emergency room personnel, and to identify differences between the groups.

\subsection{Data Collection and Participants}

Postal surveys were sent to 26 clinical directors of Swedish ambulance and emergency rooms, totally including 240 enquieries with answering envelopes (addressed to the project leader) for the directors to hand out among the ambulance and emergency room employees. To ensure confidentiality, no names of the respondents or code namnes were used, also stating there would be no second follow-up enquiery.

The 40-item job-related enquiery covered, besides the demographic questions, psychological, social, economical, and existential aspects on their frequently - often daily meetings with severely ill, dying and dead people and their families.

The questionnaire included a selection of revised items taken from Frommelt Attitude Toward Care of the Dying Scale (23), Death Attitude Profile-Revised (24, 25), Nursing Stress Scale (15), and some earlier grief studies of the authors of the present paper. In the questionnaire some lines were reserved for the respondents' personal views and rankings as well as spontaneous comments on job experiences. 


\subsection{Statistics}

Comparisons between characteristics of the 2 groups were done with Fisher exact test. $<0.05$ was defined as statistically significant.

\subsection{Ethics}

All participants were informed about the purpose of the research, could freely ignore the questionnaire handed out by their staff leader, did not write their name on any answer, were nor coded in any way on the envelope, and were therefore ensured anonymity also in the published work. The study is a part of the longitudinal Widowhood Project at Sahlgrenska University Hospital, which has been approved by the Ethical Committee of the University of Gothenburg (Dnr 253-95).

\section{Results}

We received a total of 153 answers (64\%). One questionnaire was returned blank, two were not fully completed, and three were returned too late. Data analyses were therefore made from 147 answers. Fifty-two percent of the respondents were women, $42 \%$ men, and $6 \%$ had not answered the question about gender. Of all participants, $48 \%$ were ambulance personnel and 51\% from the emergency rooms. Significantly more men than women were ambulance workers, whilst more women than men were emergency room workers $(\mathrm{p}=0.0000)$. Among the ambulance workers $31 \%$ were women and $69 \%$ men, the overall mean age being
$40.1 \mathrm{yrs}$, median $38 \mathrm{yrs}$, and SD 10.8 yrs. Among the emergency room personnel, $72 \%$ were women and $28 \%$ men, and the overall mean age 49.7 yrs, median 39.9 yrs, SD 8.4 yrs (no significant differences in age between the two groups). The age of the respondents varied between 22 and $65 \mathrm{yrs}$, and $71 \%$ in both groups had been working within the same job between 6 and 50 years. Among the ambulance workers, 50 respondents were nurses, 5 nurse assistants and 1 physician. Among the emergency room personnel 52 were nurses, 18 nurse assistants and 7 physicians.

The majority experienced a very high to rather high prevalence of severely ill or dead patients at their work place (Table 1). At hospitals with a high number of severely ill or dead patients (more at the emergency rooms compared to the ambulance), the personnel in both groups reported a significantly higher mental workload compared with hospitals with a lower number $(\mathrm{p}=0.0113)$. Among the emergency room personnel, two of three reported their job to be mentally stressful, as compared with one of three among the ambulance personnel. Providing adequate care to the acutely ill, dying and their relatives did not correlate with the experience of mental stress. More personnel at the emergency rooms expressed time pressure at work and were less satisfied with their caretaking $(p=0.0001)$ than at the ambulance. Change of work due to heavy workload was reported by one in three. Many in both groups thought that explicit care programs at work would favour their work performance, however, being more used at the ambulance employees than at the emergency rooms $(p=0.0215)$.

Table 1. Results (\%) from and comparisons (statistical significances shown) between the two study groups; ambulance workers ( $n=73$ ) and emergency room personnel $(n=74)$

\begin{tabular}{|c|c|c|c|}
\hline I find my present mental workload stressfull & Ambulance & Emergency & Diff. \\
\hline Very & 0 & 14 & ** \\
\hline Rather & 35 & 47 & \\
\hline Not very & 59 & 33 & \\
\hline Not at all & 6 & 7 & \\
\hline \multicolumn{4}{|l|}{ I find my present physical workload stressfull } \\
\hline Very & 1 & 14 & \\
\hline Rather & 39 & 34 & \\
\hline Not very & 58 & 45 & \\
\hline Not at all & 1 & 7 & \\
\hline \multicolumn{4}{|c|}{ My job has a negative impact on my social situation or family life } \\
\hline Much & 10 & 11 & \\
\hline Rather much & 25 & 27 & \\
\hline Some & 48 & 45 & \\
\hline Not at all & 18 & 17 & \\
\hline \multicolumn{4}{|l|}{ My job has a negative impact on my leasure time } \\
\hline Much & 8 & 9 & \\
\hline Rather much & 22 & 24 & \\
\hline Some & 52 & 49 & \\
\hline Not at all & 18 & 17 & \\
\hline \multicolumn{4}{|l|}{ My general health today is: } \\
\hline Very good & 37 & 40 & \\
\hline Rather good & 60 & 48 & \\
\hline Less good & 3 & 11 & \\
\hline Not good at all & 0 & 1 & \\
\hline \multicolumn{4}{|c|}{ My place of work has a prevalence of very sick and dead persons that is: } \\
\hline Too high & 0 & 3 & \\
\hline Very high & 22 & 23 & \\
\hline High & 16 & 39 & \\
\hline
\end{tabular}




\begin{tabular}{|c|c|c|c|}
\hline I find my present mental workload stressfull & Ambulance & Emergency & Diff. \\
\hline Rather high & 38 & 27 & \\
\hline Rather little & 21 & 8 & \\
\hline Little & 3 & 1 & \\
\hline \multicolumn{4}{|c|}{ I find taking care of acutely ill patients with high risk of dying to be: } \\
\hline Very stressfull & 8 & 7 & \\
\hline Rather stressfull & 37 & 49 & \\
\hline Not so stressfull & 44 & 39 & \\
\hline Not stressfull at all & 11 & 5 & \\
\hline \multicolumn{4}{|c|}{ I find taking care of relatives and bereaved people to be: } \\
\hline Very stressfull & 18 & 21 & \\
\hline Rather stressfull & 53 & 57 & \\
\hline Not so stressfull & 27 & 22 & \\
\hline Not stressfull at all & 2 & 0 & \\
\hline \multicolumn{4}{|c|}{ I make too rapid and radical actions at my job all by myself } \\
\hline Yes, always & 9 & 6 & \\
\hline Yes, often & 35 & 49 & \\
\hline No, less often & 46 & 40 & \\
\hline No, seldom & 10 & 6 & \\
\hline \multicolumn{4}{|c|}{ How do you find your present job from a financial perspective? } \\
\hline Satisfactory & 2 & 1 & \\
\hline Rather satisfactory & 32 & 21 & \\
\hline Less satisfactory & 46 & 3 & \\
\hline Not at all satisfactory & 21 & 41 & \\
\hline \multicolumn{4}{|l|}{ I experience too high time pressure in my job } \\
\hline Yes, always & 3 & 11 & $* * *$ \\
\hline Yes, often & 30 & 65 & \\
\hline No, less often & 56 & 21 & \\
\hline No, seldom & 11 & 3 & \\
\hline \multicolumn{4}{|l|}{ I experience lack of resources at my workplace } \\
\hline Yes, always & 13 & 17 & \\
\hline Yes, often & 54 & 60 & \\
\hline No, less often & 27 & 19 & \\
\hline No, seldom & 6 & 4 & \\
\hline \multicolumn{4}{|c|}{ Do you find that you can provide satisfactory care of severely ill people? } \\
\hline Yes, definitively & 41 & 16 & $* * *$ \\
\hline Yes, rather much & 59 & 72 & \\
\hline No, not very much & 0 & 12 & \\
\hline No, not at all & 0 & 0 & \\
\hline \multicolumn{4}{|c|}{ Have you been at sick leave the latest year because of too a heavy work load? } \\
\hline Yes, much & 0 & 0 & \\
\hline Yes, to some extent & 0 & 1 & \\
\hline No, not much & 9 & 7 & \\
\hline No, not at all & 91 & 92 & \\
\hline \multicolumn{4}{|c|}{ I feel insecure about the result of my care for very ill people. } \\
\hline Yes, very often & 2 & 1 & \\
\hline Yes, often & 18 & 21 & \\
\hline No, seldom & 71 & 63 & \\
\hline No, never & 10 & 15 & \\
\hline \multicolumn{4}{|c|}{ Do you belive that you have any influence on your work load? } \\
\hline Yes, much & 2 & 1 & * \\
\hline Yes, rather much & 7 & 23 & \\
\hline No, not so much & 49 & 48 & \\
\hline No, not at all & 42 & 27 & \\
\hline \multicolumn{4}{|c|}{ Do you feel that your team management is well informed with your work? } \\
\hline Yes, very much & 11 & 12 & \\
\hline Yes, rather & 43 & 43 & \\
\hline No, not so much & 30 & 35 & \\
\hline No, not at all & 16 & 11 & \\
\hline \multicolumn{4}{|c|}{ Do you think that care professionals in general get used to working with a high prevalence of severely ill, dying and deceased patients? } \\
\hline Yes, absolutely & 16 & 16 & \\
\hline Yes, rather much & 59 & 63 & \\
\hline No, not very often & 25 & 20 & \\
\hline No, never & 0 & 1 & \\
\hline \multicolumn{4}{|c|}{ Have you yourself got used to working with a high prevalence of the severly ill, dying and deceased? } \\
\hline Yes, absolutely & 23 & 25 & \\
\hline Yes, rather much & 66 & 64 & \\
\hline No, not much & 7 & 8 & \\
\hline
\end{tabular}




\begin{tabular}{|c|c|c|c|}
\hline I find my present mental workload stressfull & Ambulance & Emergency & Diff. \\
\hline No, I never will & 5 & 3 & \\
\hline \multicolumn{4}{|l|}{ Do you experience high demands at your work place? } \\
\hline Yes, too high & 2 & 11 & \\
\hline Yes, rather high & 79 & 73 & \\
\hline No, not so high & 14 & 15 & \\
\hline No, not at all high & 5 & 1 & \\
\hline \multicolumn{4}{|c|}{ How do you find the implementation of quality of care at your work? } \\
\hline High & 21 & 8 & ** \\
\hline High, but not optimal & 71 & 71 & \\
\hline Rather low & 6 & 16 & \\
\hline Unsatisfactory & 2 & 5 & \\
\hline \multicolumn{4}{|c|}{ Is there a risk for you to have to change work-assignments due to today's workload? } \\
\hline Yes, high risk & 5 & 9 & \\
\hline Yes, rather high risk & 24 & 28 & \\
\hline No, not so high risk & 44 & 41 & \\
\hline No, no risk at all & 27 & 21 & \\
\hline \multicolumn{4}{|c|}{ Would more specific care programs favour your work situation? } \\
\hline Yes, absolutely & 48 & 27 & \\
\hline Yes, possibly & 32 & 53 & \\
\hline No, hardly not & 21 & 20 & \\
\hline No, not at all & 0 & 0 & \\
\hline \multicolumn{4}{|l|}{ Are such programs applied at your work? } \\
\hline Yes, they exist and are fully used & 32 & 13 & * \\
\hline Yes, they exist but are not fully used & 61 & 73 & \\
\hline Yes, they exist but are not used & 3 & 10 & \\
\hline No, there are no such programs & 3 & 4 & \\
\hline \multicolumn{4}{|c|}{ Are there support programs for the personnel at your workplace? } \\
\hline Yes, explicit & 8 & 9 & \\
\hline Yes, rather explicit & 33 & 34 & \\
\hline Not so explicit & 43 & 45 & \\
\hline No, they do not exist & 16 & 13 & \\
\hline \multicolumn{4}{|l|}{ If Yes, are they used? } \\
\hline Yes, always & 0 & 11 & \\
\hline Yes, often & 53 & 30 & \\
\hline Seldom & 40 & 50 & \\
\hline Never & 8 & 9 & \\
\hline \multicolumn{4}{|c|}{ Do you yourself get the support and debriefing that you think you need? } \\
\hline Yes, always & 42 & 31 & \\
\hline Yes, but not enough & 16 & 35 & \\
\hline No, not suffuciently & 23 & 23 & \\
\hline No, not at all & 19 & 12 & \\
\hline \multicolumn{4}{|c|}{ Is there anything you would like to change at your job in order to be able to work with satisfaction and confidence? } \\
\hline Yes, very much & 24 & 16 & \\
\hline Yes, rather much & 51 & 47 & \\
\hline No, not so much & 22 & 36 & \\
\hline No, nothing & 3 & 1 & \\
\hline \multicolumn{4}{|l|}{ If Yes, name what! See results in table II } \\
\hline \multicolumn{4}{|l|}{ Have you been offered further education or courses? } \\
\hline Yes, often & 3 & 5 & \\
\hline Yes, rather often & 44 & 40 & \\
\hline No, not often & 40 & 45 & \\
\hline No, never & 13 & 9 & \\
\hline \multirow{2}{*}{\multicolumn{4}{|c|}{ If No, what would you prefer? If, YES, name what. Please, see results in table II }} \\
\hline & & \multicolumn{2}{|c|}{ How is your experience of the possibilities for you to advance at your work place? } \\
\hline Good 1 ( & 2 & 1 & \\
\hline Rather good & 18 & 26 & \\
\hline Not so good & 52 & 55 & \\
\hline Not good at all & 29 & 18 & \\
\hline How do you find the team composition at your $\mathrm{j}$ & & & \\
\hline Well fitting & 19 & 10 & \\
\hline Rather well fitting & 73 & 72 & \\
\hline Not very fitting & 5 & 18 & \\
\hline Not at all fitting & 3 & 1 & \\
\hline How do you find your leadership at work? & & & \\
\hline Very good & 8 & 10 & * \\
\hline Rather good & 30 & 39 & \\
\hline Less good & 29 & 43 & \\
\hline
\end{tabular}




\begin{tabular}{|c|c|c|c|}
\hline I find my present mental workload stressfull & Ambulance & Emergency & Diff. \\
\hline Not good at all & 33 & 8 & \\
\hline \multicolumn{4}{|c|}{ How do you find the support offered to bereaved relatives of the patient? } \\
\hline Very good & 1 & 11 & $* * *$ \\
\hline Rather good & 27 & 54 & \\
\hline Less good & 33 & 20 & \\
\hline Not good at all & 16 & 7 & \\
\hline \multicolumn{4}{|c|}{ Does your job place have routines for literary recommendations to the bereaved (pamphlets and information leaflets)? } \\
\hline Yes, but not satisfactory & 23 & 50 & \\
\hline No, rather unsatisfactory & 30 & 7 & \\
\hline No, none at all & 40 & 2 & \\
\hline \multicolumn{4}{|c|}{ Do you think it is important to have personal characteristics fitting for the job? } \\
\hline Yes, very & 65 & 51 & \\
\hline Yes, rather & 32 & 48 & \\
\hline No, not very & 2 & 1 & \\
\hline \multicolumn{4}{|c|}{ Do you think it is possible to get used/accommodated to the prevalence of death and grief in your profession? } \\
\hline Yes, absolutely & 24 & 24 & \\
\hline Yes, rather possible & 67 & 57 & \\
\hline No, not very possible & 8 & 16 & \\
\hline No, not possible at all & 2 & 3 & \\
\hline \multicolumn{4}{|c|}{ To what extent do you think that personnel themselves are affected by death and dying? } \\
\hline Very high extent & 5 & 11 & \\
\hline High extent & 49 & 42 & \\
\hline Rather high extent & 44 & 47 & \\
\hline Little & 0 & 0 & \\
\hline \multicolumn{4}{|c|}{ To what extent will the job satisfaction and well-being be influenced by death and dying? } \\
\hline Very much & 12 & 7 & \\
\hline Much & 39 & 45 & \\
\hline Rather little & 48 & 45 & \\
\hline Not at all & 2 & 3 & \\
\hline \multicolumn{4}{|c|}{ Do you think that further education would improve job satisfaction? } \\
\hline Rather little & 16 & 18 & \\
\hline Not at all & 4 & 0 & \\
\hline
\end{tabular}

$*$ Refers to $\mathrm{p}<0.05, * *$ refers to $\mathrm{p}>0.01, * * *$ refers to $\mathrm{p}<0.001$, significant difference between the two study groups

Rather few respondents in both groups found explicit personnel support programs or manuals at work, and when so, they were seldom fully used. The majority also wished for changes at their workplace to be able to work with satisfaction and safety, including being offered debriefing and further education. The possibilities for advancement at work were experienced to be low or non-existing among over $70 \%$. Many found the management/leadership to be less informed and good, especially among the ambulance workers $(p=0.0160)$, but found on the other hand the composition of the team fit for the care situation. Personal suitability for the job was considered necessary by almost all. The majority also thought that it was possible (for themselves and other care professionals) to get used to a job with dying, dead and grieving, but about half of them thought that wellbeing was negatively affected by patients' deaths. The workload also seemed to influence the social situation and leisure time to a substantial degree.

The majority of the responders still reported good or rather good health, and had not been on sick leave due to excessive workload. Lack of influence on their own workload was, however, substantial and also reported by more people working at the emergency rooms $(p=0.0376)$. Lack of resources at work was also commonly reported. Both groups found the demands at work equally high. However, ambulance workers found their quality of care better as compared with emergency room personnel $(p=0.0083)$. One in five employees felt insecure/uncertain about the result of their care among very ill people.

In total, more women than men in both ambulance and emergency rooms considered their mental workload as straining ( $57 \%$ and $44 \%$ respectively, $p=0.0073)$, but more men than women reported the physical workload to be straining ( $63 \%$ and $38 \%$, respectively, $\mathrm{p}=0.0468)$. One third of all personnel felt that they had to provide too rapid and radical care on their own, and almost half of them had the impression that their work management were not particularly or not at all updated on the care that their staff performed. Few were very satisfied with their salary.

Among factors rated most positively experienced, the personnel at both ambulance and emergency rooms reported their working partners, colleagues, and the team as a whole. Personnel at the ambulance found freedom (under responsibility), challenge, variation and excitement frequently mentioned. These variables were "rather frequently" named among the emergency room personnel, where caretaking, saving lives, meaningfulness, and grateful patients were common words of honor. 
Among the ambulance workers, the factors generally critical for becoming worked-out and sick leave at the investigated work areas were physically high workload and physical damage, mental stress (specially at children trauma), shift- and night work. The emergency room personnel mostly named stress and high tempo, low quality of their mental and physical work situation, inconvenience regarding shift and weekend work, high flow of patients, and a lack of competent personnel.

Many mentioned a lack of leadership and resources, too little time for debriefing and recovery, crisis support, and guidance as generally critical factors. These critical factors were often also reported as personally experienced ones, as long and irregular shifts, lack of time for sleeping and eating, unclear management with substandard communication and feedback, lack of credit as well as support.

About half of the ambulance and emergency room workers found it "very" or "rather" stressfull taking care of patients at high risk of dying. About seven out of ten among both ambulance and emergency room personnel also found it stressful taking care of relatives and bereaved persons. "Good" or "rather good" bereavement support was reported by more emergency room workers, and these had better routines for recommendations to the bereaved, e.g. through pamphlets and information leaflets, compared with workers at the ambulance $(p=0.0000)$. However, half of the acute workers were not fully satisfied.

Table 2. Ranking of factors that could improve the endurance at the present job

Ambulance workers' ranking list

1. Shorter working hours

2. Longer vacation leave

3. Less shift work

4. Alternative team constitution

5. Miscellaneous

6. Raised salary

7. Improved management

8. Clearer work duties

9. Greater individual influence

Emergency room personnel's ranking list

1. Shorter working hours

2. Longer vacation leave

3. Less shift work

4. Raised salary

5. Improved management

6. Clearer work duties

7. Greater individual influence

8. Alternative team constitution

9. Miscellaneous

When ranking factors critical for coping at work, most of the employees at both ambulance and emergency rooms named shorted working hours and longer vacation leave as number one and two, respectively (Table 2). Salary and other working schedules were other improvements asked for. Better team leaders, increased influence and better routines were also factors asked for. Other wishes were more personnel, plans for prioritations, less work on holidays, higher physician competency around the clock (more trained doctors in acute medicine), time for physical training, increased professional knowledge, and more ambulance driving training.

\section{Discussion}

The results provided us with a picture of acute caretaking among ambulance and acute emergency personnel in everyday dealing with death and dying, stress, perceived control, understaffing, and coping. Like other researchers in this area $(11,14,20,26,27)$ we found a variety of self-reported stressors and needs in coping to reduce e.g. work-based stress, personal inner strength, organizational arrangements, emotional exhaustion, and feelings of lack of personal accomplishment. Identification of such factors might help to reduce levels of experienced stress and exhaustion. Employees at risk for burn out in our study seemed to be few, as the reports on sick-leave were little, the respondents' health were generally good, and both adaptation to and personal characteristics to meet dying and dead people seemed adequately present in both ambulance and emergency room personnel.

Gender differences existed for both study groups. More women complained of mental stress while more men found physical stress hard to handle. On the other hand, the reported differences between the groups were rather few. The emergency room personnel, who also reported a higher number of severely ill and dead persons, and dissatisfaction with their work performance and quality, seemed to suffer from a lack of time to follow the unit care programs.

Both occupational groups were faced with death exposure, however, to a different extent due to the prevalence of dying and dead arriving at the intake of the hospital. Heavy workload, poor staffing, frequent dealing with death and dying, inter-staff conflicts, strain of shift work, careers, and lack of resources and organizational support have been identified as major sources of job stress in this study like many other investigations among emergency services personnel (14). Mental preparation is said to be important before the arrival at the scene of the accident, but was not studied here. In our study the personal suitability for the job seemed on the other hand rather well accounted for.

The mental health and emotional well being of ambulance personnel appear to be compromised by accident and emergency work. Marmar and co-workers (6) stated that rescue workers who are shy, inhibited, uncertain about their identity, or reluctant to take on leadership roles, who believe their fate is determined by factors beyond their control, and who cope with critical incident trauma by emotional suppression and wishful thinking, are at a higher risk for acute dissociative responses to trauma and subsequent posttraumatic stress disorder.

Nursing professionals working in emergency care often suffer from physical symptoms according to Farias and coworkers (12). According to the workers in their study, pain always resulted from emotional stress or appeared after providing emergency care, which suggests that the workers 
find it very difficult to differentiate physical from mental stress. In our study mostly men at the ambulance complained about physical workload, however, not being further studied if this relationship also existed here.

According to many studies $(7,20,26)$ emergency room personnel are at risk to develop health symptoms due to work related stressors. Although, acute stressors are related to health symptoms, such as fatigue, burnout, and posttraumatic symptoms, they have not been found to predict health symptoms in a long-term perspective (20). Main risk factors have to do with social aspects of the work environment, e.g. lack of support from the supervisor and colleagues as well as poor communication. Workplace interventions should take these social aspects need into account.

In our study health was generally reported to be good, contradicting several other findings among paramedics. Hegg and co-workers (28) found that paramedics accumulate a set of risk factors, including acute and chronic stress, which may even lead to a development of cardiovascular diseases. However, their employers used no inquiry or control methods to monitor the workers' health status and cardio-respiratory fitness. Alexander and Klein (29) concluded that the mental health and emotional well being of ambulance personnel appear to be compromised by accident and emergency work. More studies are needed to characterize paramedics' behaviour at work. These studies could allow the development of targeted strategies to prevent health problems reported in paramedics.

The age of the responders and the years of work did not predict work overload and stress in our study. However, in a study of Craig and Sprang (7) age and years of experience proved to be powerful predictors with younger professionals reporting higher levels of burnout versus more experienced providers endorsing higher levels of compassion satisfaction. According to a study by Nirel and co-workers (26) it seems to exist a need to reconsider the optimum length of service in the paramedical profession to counteract burnout, and a need to form organizational arrangements to change the work procedures of aging paramedics. This might support our findings of needs for shorter working hours and longer vacations to balance out straining shift work. To be too tired to work might constitute negative effects caused by the effects of working with emergency care (9).

Most of the ambulance and emergency room workers in this study (with many years in the field) had been confronted with accumulative acute stressors, being overburdened and understaffed in the intensive care unit. However, despite frequently reporting job strain and mental stress, e.g. including lack of time, poor support and leadership, left on one's own with radical decision-making, not being informed about important decisions, and general high demands, surprisingly few had not been on sick leave caused by too high a workload. This stands in stark contrast to many other studies on high psychological demands, emotional exhaustion, and cumulative exposure to stress sometimes leading to PTSD $(27,29-32)$. It could be that few responders had experienced a particularly disturbing incident in the previous six months, which is said to be predictive for severe consequences at emergency work. Furthermore, recognising signs of burnout taking the assessment form for PTSD was not the main purpose of our study, as in several studies on emergency workers studying e.g. the effects of work trauma in longer or shorter terms of time elapse (33). In general, post-trauma activities should include individual follow-up debriefing, e.g. to counteract stress disorders. In our study groups the need for better debriefing routines and support programs were emphasized. The endurance at work in our two-study-groups could also be partly explained by not knowing anything about the situation of the non-responders for comparison of endurance.

Poor or hindering communication with the staff leader might be balanced by debriefing within the team and colleagues to rely on and communicate with and receive support from (34). According to Jungert (35), colleagues motivate their co-workers better than the management. He found that the importance of the team is based on critical factors as feeling competent, being autonomous and feeling related to others in the team. These findings seemed to yield also in our study, many reporting good health, very little sick leave, and no thoughts of quitting their present job, although perceiving them to be poorly paid. Clinical handover of patients between two organisations - ambulance and emergency room workers - with somewhat different cultures and backgrounds may need improved strategies through e.g. shared training programmes (22).

Interesting findings were the similarities in both study groups in regards to ranking improvements in favour for higher job satisfaction, and preferably focusing on shorter working-hours, longer vacation leaves, more satisfactory planned shift schedules, increased salary and improved management.

Several studies have underlined the importance of feedback from the management and acknowledgment for a job good made (36). This was also frequently wished for by responders in our study. This lack of positive support och acknowledgement from the management might have been counterbalanced among the respondents in our study by credit from colleagues and relatives to patients, as well as their own inner feelings of satisfaction with their workperformance. The common wish for greater individual influence at work might also meet the criteria of acknowledgement from the staff management.

Perceived job control, self-efficacy, self-esteem, perceived unit efficiency, clearer work duties, increased salary, improved management, influence at work, acceptance of death attitude, more leisure time, and non-conflicting family interests could reduce the effect of job strain on risk of personal burnout in this study as in line with the results of several other studies on the subject $(14,20,37,38)$. In addition, education and training could certainly help professionals at the ambulance and emergency rooms to further deal with coping. In our study, there existed frequent demands on increased education and training, as this 
probably also would increase possibilities for career advancement. Organizations should support professionals especially when it comes to children and trauma $(34,39,40)$.

Bereaved subjects should be met with more caring facilities, including support and follow up by personnel as well as pamphlets to take home after being faced with a traumatic experience. A good example of this was performed at the emergency room at the Uppsala University Hospital in Sweden a few years ago. At the emergency room, the ambulance staff was greeted at the intake by a nurse assistant specially trained and focused on providing support to close relatives of the patient during the acute phase and afterwards up to two months post loss (41). In order to meet patients' psychosocial needs effectively, researchers in the field $(4,42,43,44)$ state that emergency workers should be offered psychosocial training in a number of skills for their own psychosocial support to be enhanced. Palliative care, meaning a "good death," free from pain and suffering for the patient and the patient's family would seem to have little to do with acute care delivered in a setting such as the emergency department. Less suitable predispositions might also have been present for our study groups, especially finding mental stress to be significantly related to reports on working with many dying persons. Not having enough personnel, time, routines, and equipment could result in an increased feeling of dissatisfaction with work performance and outcome, and left the workers with stress both at work and in private life.

Several critical factors seemed important for job satisfaction among Swedish ambulance workers and personnel at the emergency rooms. Complaints about psychological stress, physically high workload, physical damage, many working hours, low salary, much shift- and night work, better vacation leave, more resources, too little time for recovery, crisis support and guidance, better routines, more explicit care programs including improved bereavement support for relatives, better possibilities for job control, selfefficacy, unit efficiency, and clearer work duties, and a family-non-conflicting job situation could favour work performance in both groups.

\section{Acknowledgments}

We thank Valter Sundh, BSc. for invaluable help with the data processing.

\section{Funding}

The authors acknowledge the support of AFA Insurance, Sweden.

\section{References}

[1] Holmes T, Rahe R. "Holmes-Rahe Social Readjustment Rating Scale". J Psychosom Res 1967; vol. II, 213-218.

[2] Gilliland G, Fleming S. A comparison of spousal anticipatory grief and conventional grief. Death Stud 1998; 22: 541-569.
[3] Nakajima S, Ito M, Shirai A, Konishi T. Complicated grief in those bereaved by violent death: the effects of post-traumatic stress disorder on complicated grief. Dial Clin Neurosci 2012; 14: $210-214$.

[4] Kristensen P, Weisæth L, Heir T. Bereavement and mental health after sudden and violent losses: a review. Psychiatr 2012; 75: 76-97.

[5] Carr M, Pratt Merriman J. Comparison of Death Attitudes among Hospice Workers and Health Care Professionals in Other Settings. Omega: J Death Dying 1995-1996; 32: 287301 .

[6] Marmar CR, Weiss DS, Metzler TJ, Delucchi K. Characteristics of emergency services personnel related to peritraumatic dissociation during critical incident exposure. Am J Psychiatr 1996; 153: 94-102.

[7] Craig CD, Sprang G. Compassion satisfaction, compassion fatigue, and burnout in a national sample of trauma treatment therapists. Anxiety, Stress \& Coping 2010; 23: 319-339.

[8] Clohessy S, Ehlers A. PTSD symptoms, response to intrusive memories and coping in ambulance service workers. Br J Clin Psychol 1999; 38: 251-265.

[9] Collins S, Long A. Too tired to care? The psychological effects of working with trauma. $J$ Psychiatr Ment Health Nurs 2003; 10: 17-27.

[10] Iranmanesh S, Häggström $\mathrm{T}$, Axelsson $\mathrm{K}$, Sävenstedt $\mathrm{S}$. Swedish nurses' experiences of caring for dying people; a holistic approach. J Holist Nurs Pract 2009; 23: 243-252.

[11] Lundman B, Viglund K, Aléx L, Jonsén, E, Norberg A, Fischer RS, Strandberg G, Nygren, B. Development and psychometric properties of the Inner Strength Scale. Int J Nurs Stud 2011; 48: 1266-1274.

[12] Farias SM, Teixeira OL, Moreira W, Oliveira MA, Pereira MO. Characterization of the physical symptoms of stress in the emergency health care team. Rev Esc Enferm USP 2011; 45: 722-729.

[13] Lange M, Thom B, Kline NE. Assessing nurses' attitudes toward death and caring for dying patients in a comprehensive cancer center. Oncol Nurs Forum 2008; 35: 955-959.

[14] Linley PA, Joseph S. Positive and negative changes following occupational death exposure. J Traum Stress 2005; 18: 751758.

[15] French SE, Lenton R, Walters V, Eyles, J. An empirical evaluation of an expanded Nursing Stress Scale. J Nurs Measur 2000; 161-178.

[16] Braun M, Gordon D, Uziely B. Associations between oncology nurses' attitudes toward death and caring for dying patients. Oncol Nurs Forum 2010; 37: 43-49.

[17] Kinoshita S, Miyashita M. Development of a scale for "difficulties felt by ICU nurses providing end-of-life care". Intens Crit Care Nurs 2011; 27: 202-210.

[18] Shimoinaba K, O'Connor M, Lee S, Greaves J. Staff grief and support systems for Japanese health care professionals working in palliative care. Pall Supp Care 2009; 7: 245-252.

[19] Vejlgaard T, Addington-Hall JM. Attitudes of Danish doctors and nurses to palliative and terminal care. Palliat Med 2005; 19: 119-127. 
[20] Stordeur S, Vandenberghe C, D'hoore W. Predictors of nurses' professional burnout: a study in a university hospital. Rech Soin Infirm 1999; 59: 57-67.

[21] Edwards D, Burnard P, Coyle D, Fothergill A, Hannigan B. A stepwise multivariate analysis of factors that contribute to stress for mental health nurses working in the community. Emerg Med J 2001; 36: 805-813.

[22] Hermansen M, Lennholm T. 'Prehospital triage to improve patient safety by shorten lead times associated with the handover of patient care between ambulance and emergency department.' Report, Luleå University, Sweden 2011.

[23] Frommelt KH. Attitudes toward care of the terminally ill: an educational intervention. Am J Hosp Pall Care 2003; 20: 1322.

[24] Wong TPT, Reker GF, Gesser G. 'Death Attitude ProfileRevised: A multidimensional measure of attitudes toward death'. In Death Anxiety Handbook: Research, Instrumentation, and Application (Neimeyer RA ed.), 1994 Taylor \& Francis, Washington DC, 527-534.

[25] Cicirelli VG. Sibling death and death fear in relation to depressive symptomatology in older adults. $J$ Gerontol $B$ Psychol Sci Soc Sci. 2009; 64 : 24-32.

[26] Nirel N, Goldwag R, Feigenberg Z, Abadi D, Halpern P. Stress, work overload, burnout, and satisfaction among paramedics in Israel. Prehosp Disas Med 2008; 23: 537-546.

[27] Ward NS, Read R, Afessa B, Kahn, JM. Perceived effects of attending physician workload in academic medical intensive care units: a national survey of training program directors. Crit Care Med 2012; 40: 400-405.

[28] Hegg-Deloye S, Brassard P, Jauvin N, Prairie J, Larouche D, Poirier P, Tremblay A, Corbeil, P. Current state of knowledge of post-traumatic stress, sleeping problems, obesity and cardiovascular disease in paramedics. Emerg Med J 2013 Jan 12 .

[29] Alexander DA, Klein S. Ambulance personnel and critical incidents. Impact of accident and emergency work on mental health and emotional well being. BJP 2001; 178: 76-81.

[30] Jonsson A, Segesten K, Mattsson B. Post-traumatic stress among Swedish ambulance personnel. Emerg Med J 2003; 20: 79-84.

[31] Gunnarsson B-M, Warrén Stomberg M. Factors influencing decision making among ambulance nurses in emergency care situations. Int Emerg Nurs 2009; 17: 83-89.

[32] Wireklint Sundström B, Dahlberg K. Caring assessment in the Swedish ambulance services relieves suffering and enables safe decisions. Int Emerg Nurs 2011; 19: 113-119.

[33] de Boer J, Lok A, Van't Verlaat E, Duivenvoorden HJ, Bakker
AB, Smit BJ. Work-related critical incidents in hospital-based health care providers and the risk of post-traumatic stress symptoms, anxiety, and depression: A meta-analysis. Soc Sci Med 2011; 73: 316-326.

[34] Shepherd L, Wild J. Cognitive appraisals, objectivity and coping in ambulance workers: a pilot study. Emerg Med $J$ 2013 Jan 16.

[35] Jungert T. 'Self-efficacy, Motivation and Approaches to Studying: A longitudinal study of $Y$ and how engineering students perceive their studies and transition to work.' $\mathrm{PhD}$ thesis. University of Linköping, Sweden 2009.

[36] Abelsson A, Lindwall L. The Prehospital assessment of severe trauma patients ' performed by the specialist ambulance nurse in Sweden - a phenomenographic study. Scand J Trauma Resusc Emerg Med 2012; 20: 67.

[37] Everly GS. 'Familial psychotraumatology and emergency service personnel' pp. 42-50 in Innovations in disaster and trauma psychology. Volume 1: applications in emergency services and disaster response. Chevron, Ellicott City, Maryland 1995.

[38] Bost N, Crilly J, Patterson E, Chaboyer W. Clinical handover of patients arriving by ambulance to a hospital emergency department: a qualitative study. Int Emerg Nurs 2012; 20: 133-141.

[39] Maia AC, Ribeiro E. The psychological impact of motor vehicle accidents on emergency service workers. Eur J Emerg Med 2010; 17: 296-301.

[40] Elmqvist C, Brunt D, Fridlund B, Ekebergh M. Being first on the scene of an accident-experiences of 'doing' prehospital emergency care. Scand J Car Sci 2010; 24: 266-273.

[41] Grimby A, Lundmark K, Marklund A, Simson C, Sundh V. Anhörigas utsatthet och omhändertagande vid olycka, svår sjukdom och sorg. En interventionsstudie på akutmottagning. Report, Uppsala Akademiska sjukhus, 2010. (Swedish)

[42] Hansen CD, Rasmussen K, Kyed M, Nielsen KJ, Andersen JH Physical and psychosocial work environment factors and their association with health outcomes in Danish ambulance personnel - a cross-sectional study. BMC Public Health 2012;12:534.

[43] Prati G, Pietrantoni L, Cicognani E. Self-efficacy moderates the relationship between stress appraisal and quality of life among rescue workers. Anxiety, Stress \& Coping 2010; 23: 463-470.

[44] Drury J, Kemp V, Newman J, Novelli D, Doyle C, Walter D, Williams R. Psychosocial care for persons affected by emergencies and major incidents: a Delphi study to determine the needs of professional first responders for education, training and support. Emerg Med J 2013; 30: 831-836. 